Article

\title{
Bone Regeneration Using Adipose-Derived Stem Cells in Injectable Thermo-Gelling Hydrogel Scaffold Containing Platelet-Rich Plasma and Biphasic Calcium Phosphate
}

\author{
Han Tsung Liao ${ }^{1,2,3}$ (D), Ming-Jin Tsai ${ }^{2}$, Manuri Brahmayya ${ }^{1}$ and Jyh-Ping Chen $1,2,4,5, *$ (D) \\ 1 Department of Plastic and Reconstructive Surgery and Craniofacial Research Center, \\ Chang Gung Memorial Hospital, Chang Gung University School of Medicine, Kwei-San, \\ Taoyuan 33305, Taiwan; lia01211@gmail.com (H.T.L.); brahma.orgchem@gmail.com (M.B.) \\ 2 Department of Chemical and Materials Engineering, Chang Gung University, Kwei-San, \\ Taoyuan 33302, Taiwan; duo8704024@hotmail.com \\ 3 College of Medicine, Chang Gung University, Kwei-San, Taoyuan 33302, Taiwan \\ 4 Research Center for Food and Cosmetic Safety, Research Center for Chinese Herbal Medicine, \\ College of Human Ecology, Chang Gung University of Science and Technology, Taoyuan 33302, Taiwan \\ 5 Department of Materials Engineering, Ming Chi University of Technology, Tai-Shan, \\ New Taipei City 24301, Taiwan \\ * Correspondence: jpchen@mail.cgu.edu.tw; Tel.: +886-3-211-8800 (ext. 5298)
}

Received: 27 July 2018; Accepted: 24 August 2018; Published: 27 August 2018

\begin{abstract}
For bone regeneration, a biocompatible thermo-gelling hydrogel, hyaluronic acid- $g$ chitosan- $g$-poly(N-isopropylacrylamide) (HA-CPN) was used as a three-dimensional organic gel matrix for entrapping rabbit adipose-derived stem cells (rASCs). Biphasic calcium phosphate (BCP) ceramic microparticles were embedded within the gel matrix as a mineralized bone matrix, which was further fortified with platelet-rich plasma (PRP) with osteo-inductive properties. In vitro culture of rASCs in HA-CPN and HA-CPN/PRP/BCP was compared for cell proliferation and osteogenic differentiation. Overall, HA-CPN/PRP/BCP was a better injectable cell carrier for osteogenesis of rASCs with increased cell proliferation rate and alkaline phosphatase activity, enhanced calcium deposition and mineralization of extracellular matrix, and up-regulated expression of genetic markers of osteogenesis. By implanting HA-CPN/PRP/BCP/rASCs constructs in rabbit critical size calvarial bone defects, new bone formation at the defect site was successfully demonstrated from computed tomography, and histological and immunohistochemical analysis. Taken together, by combining PRP and BCP as the osteo-inductive and osteo-conductive factor with HA-CPN, we successfully demonstrated the thermo-gelling composite hydrogel scaffold could promote the osteogenesis of rASCs for bone tissue engineering applications.
\end{abstract}

Keywords: scaffold; hydrogel; thermo-gelling; biphasic calcium phosphate; platelet-rich plasma; adipose-derived stem cells

\section{Introduction}

Autogenous bone graft and bone substitutes are current approaches for bone defect repair after trauma, tumor ablation or infection [1]. Nevertheless, these approaches all have drawbacks such as an unpredictable absorption rate, donor site morbidity, foreign body reaction, possible infection and unpredictable bone regeneration [2]. For the healing of bone defects, a tissue engineering approach combining stem cells with osteogenic property with a suitable scaffolding material can 
be suggested. Therefore, bone tissue engineering (BTE) is now a popular research topic for bone defect repair/regeneration, which consists of three main factors, i.e., cells, scaffolds and growth factors [3]. The revelation of such an idea is that stem cells could be osteo-induced into the osteoblast lineage by the action of growth factors that function as signaling molecules within the bone-mimetic three-dimensional (3D) scaffold for bone tissue formation [4].

Bio-ceramics such as calcium phosphates are attractive for BTE applications due to their biocompatibility, bioactivity, degradability and osteo-conductivity [5]. In addition, an added advantage of using calcium phosphates is their structural and chemical similarity to the mineral phase of native bone [6]. The most widely investigated calcium phosphates that are used for bone regeneration and repairs are hydroxyapatite (HAP), $\beta$-tricalcium phosphate $(\beta-\mathrm{TCP})$, and their mixture biphasic calcium phosphate (BCP). As an ideal bone substitute, $\mathrm{BCP}$ is the preferred ceramic material, due to its controllable degradability, high bio-resorption rate and favorable biological properties [7]. Indeed, evolution of the concept of using macroporous BCP, which contained HAP and $\beta$-TCP mixed in various ratios, for bone regeneration has been reported nearly 30 years ago $[8,9]$. The usefulness of BCP stemmed from the preferential dissolution of $\beta$-TCP compared to HAP, which allowed the manipulation of the biodegradation rate of $\mathrm{BCP}$ with different HAP/ $\beta-\mathrm{TCP}$ ratios [10]. Although calcium phosphates are known to enhance osteoblast proliferation and differentiation, these ceramic materials are brittle and difficult to mold in order to fill irregular bone defects $[11,12]$. Besides, the dispersion of calcium phosphate particles during implantation may be difficult in both ectopic and bony sites [13].

Hydrogels are soft materials with 3D cross-linked network formed from hydrophilic homopolymers or copolymers. Other than using their 3D networks for cell entrapment, hydrogels can absorb a large amount of water and allow for diffusion of nutrients and metabolites from the cells. As a scaffolding material for tissue engineering applications, hydrogels could fulfill the requirement to temporarily provide an extracellular matrix (ECM) environment for the cells during the early stage of tissue regeneration [14]. This will be followed by replacement of the hydrogel matrices by a natural ECM secreted by the cells as the tissue formation process proceeds [15].

By responding to environmental stimuli for sol-to-gel transition, such as change in temperature, $\mathrm{pH}$, light or ionic strength, a physical in situ forming hydrogel is one of the most popular injectable scaffolds for BTE [16]. Using the in situ forming hydrogel, an injectable scaffold could be molded to fit a bone defect of irregular shape, shorten the operation time, lessen the post-operative discomfort and fasten post-surgical recovery. In view of the popularity of minimally invasive surgery, cell delivery in such an injectable hydrogel scaffold by endoscope could be suggested as a feasible clinical application of BTE [17]. Being a particular kind of injectable in situ forming hydrogel responsive to temperature change, a thermo-gelling hydrogel shows sol-to-gel phase transition upon heating up to a temperature above its critical transition temperature $[18,19]$. Poly(N-isopropyl acrylamide) (PNIPAM) is a typical thermo-gelling polymeric hydrogel commercially available in the market. However, non-biodegradability, low biocompatibility and the toxicity of degradation products limit its biomedical applications [20,21]. Therefore, PNIPAM has been modified with many natural polymers, including chitosan, collagen, or hyaluronic acid, to form PNIPAM-based copolymers with better biodegradability, increased cell attachment and improved cell proliferation, without changing the sol-to-gel phase transition characteristics [22-25].

Chitosan is a linear polysaccharide derived from chitin and composed of glucosamine and $\mathrm{N}$-acetyl glucosamine linked by $\beta(1 \rightarrow 4)$ covalent bonds. In recent years, biomaterials based on chitosan have been applied in BTE, which was demonstrated to be osteo-inductive, and promote cell proliferation and mineral-rich matrix deposition when used for osteoblast culture [26]. Interestingly, previous studies have reported that chitosan-modified calcium phosphates could enhance the mechanical strength of the inorganic phase when used as a scaffold for BTE applications [27,28]. Hyaluronic acid (HA) is a non-sulfated glycosaminoglycan formed from repeating disaccharide units of N-acetyl-D-glucosamine and D-glucuronate with $\beta(1 \rightarrow 4)$ and $\beta(1 \rightarrow 3)$ bonds. HA was shown to 
have strong effects on cell-cell interactions and migration [29]. As a scaffold for BTE, HA-based materials were proved to be suitable for bone regeneration in many studies [30,31].

Considering the advantages of those natural biomaterials for BTE, we have successfully prepared a thermo-gelling hydrogel copolymer, hyaluronic acid-g-chitosan- $g$-poly( $\mathrm{N}$-isopropylacrylamide) (HA-CPN) and demonstrated its potentials as a BTE scaffold using bone marrow-derived stem cells from in vitro and in vivo ectopic bone formation studies [32]. Follow up studies by incorporation of osteo-conductive BCP microparticles into a HA-CPN scaffold further proved HA-CPN/BCP to be a suitable injectable composite hydrogel scaffold for human fetal osteoblast culture with improved osteoblastic differentiation and ECM mineralization, which formed ectopic bone tissue from nude mice subcutaneous implantation experiments [33]. Nonetheless, osteoblasts are not a good cell source for BTE. Adult stem cells are better sources due to their ability of self-renewal and multi-potent differentiation. Among them, adipose-derived stem cells (ASCs) seemed to be a preferred cell source for clinical application as harvesting adipose tissue is easy and safe using local anesthesia. Furthermore, higher amount of ASCs within fat tissue could be harvested compared to harvesting bone marrow-derived stem cells from the bone marrow aspirate and the harvesting procedure is associated with less donor site morbidity [34].

As stated before, growth factor is also one of the key components for BTE. Therefore, scaffolds for enhanced bone regeneration should be endowed with growth factors retaining and releasing properties to mediate accelerated bone regeneration. Indeed, allografts and xenografts are combined with growth factors as the osteo-inductive substances for natural bone-like performance [35]. Consider that a complete bone healing cascade depends on a wide range of growth factors, it could be suggested that incorporation of a spectrum of necessary growth factors would be a more rational approach compared with solely relying on a specific growth factor for BTE [36].

Platelets in the blood play an important role during the early stage of wound healing by taking part in blood clot formation and creating the right microenvironment to guide and control the healing cascade [37]. For more efficient bone repair by external use of platelets, enriching platelets in the plasma by removing red blood cells represents a feasible approach. This enriched blood plasma, platelet-rich plasma (PRP), is a promising alternative approach to enhance bone formation as it is a rich source of growth factors originating from $\alpha$-granules in PRP, which contain various growth factors, such as platelet-derived growth factor, transforming growth factor- $\beta$, epidermal growth factor, insulin growth factor and vascular endothelial growth factor [38,39]. Abundant examples in the literature have addressed the positive effects of PRP on bone regeneration by combining with different biomaterials and various cell sources [40]. Improvement of osteogenesis of ASCs by PRP was also confirmed in a previous study by us [41]. Therefore, we hypothesize the incorporation of PRP and BCP as the osteo-inductive and osteo-conductive factor in the thermo-gelling hydrogel HA-CPN would influence the osteogenesis of ASCs.

To test this hypothesis, we evaluate the biological response of rabbit adipose-derived stem cells (rASCs) in HA-CPN and HA-CPN/PRP/BCP scaffolds in this study. The injectable scaffolds were first compared for rASCs differentiation into the osteogenic phenotype in vitro, followed by evaluation of HA-CPN/PRP/BCP composite scaffolds seeded with rASCs for regeneration of critical-size rabbit cranial defects in vivo.

\section{Results and Discussion}

\subsection{Cell Proliferation}

As an autogenous blood fraction without transmissible infectious agents, PRP is endowed with preferred properties for clinical use such as a high platelet concentration and being free from hypersensitivity reactions [42]. The platelet concentration in our prepared PRP was determined to contain $3.2 \pm 0.4 \times 10^{9}$ platelet $/ \mathrm{mL}$, which is $\sim 10$ times that in the blood collected for preparing PRP. 
It should be noted that a platelet concentration higher than $1 \times 10^{9}$ platelet $/ \mathrm{mL}$ was reported to be suitable for the clinical application of PRP [38].

As shown in Figure 1, rASCs proliferated steadily in HA-CPN and HA-CPN/PRP/BCP from day 7 to day 28 as revealed from the continued increase of the optical density $\left(\mathrm{OD}_{490}\right)$ value using the 3-(4,5-dimethylthiazol-2-yl)-5-(3-carboxymethoxyphenyl)-2-(4-sulfophenyl)-2H-tetrazolium (MTS) cell proliferation assay kit, which is directly correlated with the number of viable cells. At the same seeding density, there were more viable cells in HA-CPN/PRP/BCP than in HA-CPN with significant difference found throughout the culture period $(p<0.05)$, which indicates HA-CPN/PRP/BCP provided a better environment for rASCs proliferation than HA-CPN. This result is consistent with a previous report showing HA/gelatin/PRP hydrogel loaded in BCP scaffolds could enhance proliferation rate of MC3T3-E1 pre-osteoblast cells [43]. We also reported that incorporation of BCP into HA-CPN could significantly raise the cell proliferation rate of human fetal osteoblastic cells due to the beneficial effects of BCP [44]. Furthermore, enhancement of proliferation rate of ASCs by PRP was reported by us [45] and confirmed by other groups [46,47]. The use of rASCs in HA-CPN/PRP/BCP is expected to play a crucial role in the treatment of bone defect as recent studies on BTE clearly demonstrated the strong commitment of ASCs towards the osteogenic phenotype under appropriate induction conditions [48].

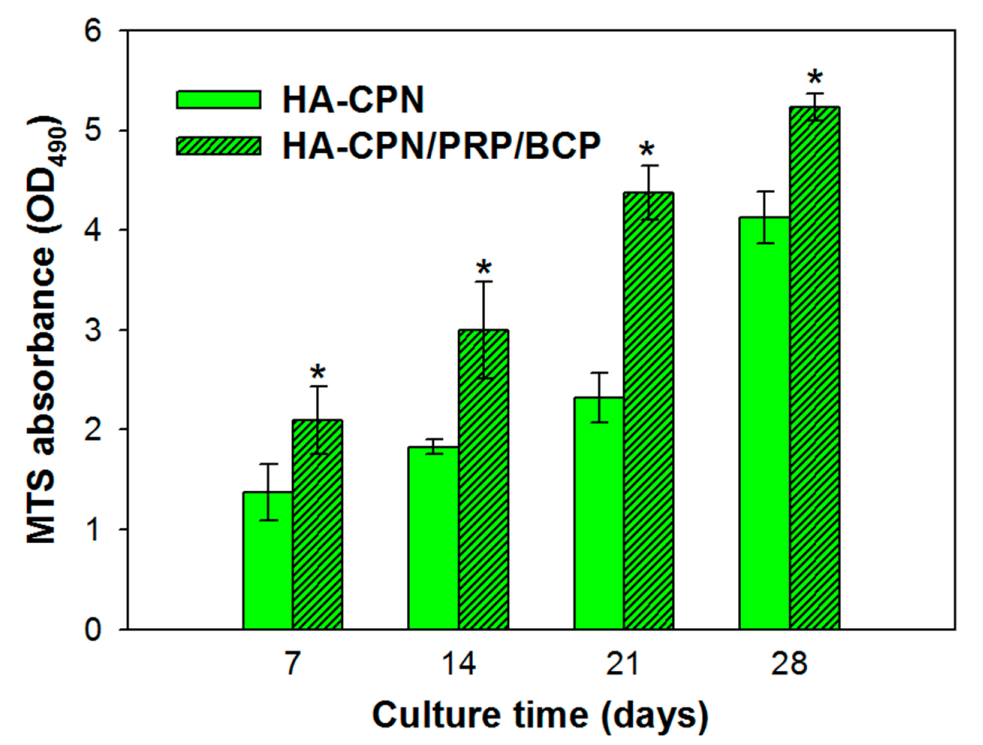

Figure 1. Proliferation of rabbit adipose-derived stem cells (rASCs) in hyaluronic acid-g-chitosan- $g$-poly (N-isopropylacrylamide) (HA-CPN) and HA-CPN/platelet-rich plasma (PRP)/biphasic calcium phosphate (BCP) thermo-gelling hydrogel scaffolds. ${ }^{*} p<0.05$ compared with HA-CPN.

\subsection{Live/Dead Staining}

After using MTS assays to confirm the increase of viable cell number in different hydrogels, the Live/Dead fluorescence cell staining assay was used to qualitatively confirm the viability of rASCs with green color representing live cells and red color identifying any possible dead cells. As shown in Figure 2, the Live/Dead staining result revealed high viability of rASCs in both HA-CPN and HA-CPN/PRP/BCP with negligible dead cells found from the confocal image, which underlines the biocompatibility of all hydrogel scaffolds. The number of viable cells (green fluorescence) also gradually increased from day 14 to day 28 for both groups. Nonetheless, more cells were found in $\mathrm{HA}-\mathrm{CPN} / \mathrm{PRP} / \mathrm{BCP}$ than in HA-CPN, which is consistent with the MTS results shown in Figure 1. In addition, rASCs started to show a cuboidal morphology of osteoblasts in HA-CPN/PRP/BCP on day 14, indicating accelerated differentiation of cells toward the osteogenic lineage [49]. Taken together, the biocompatibility of HA-CPN/PRP/BCP towards rASCs could be confirmed. 


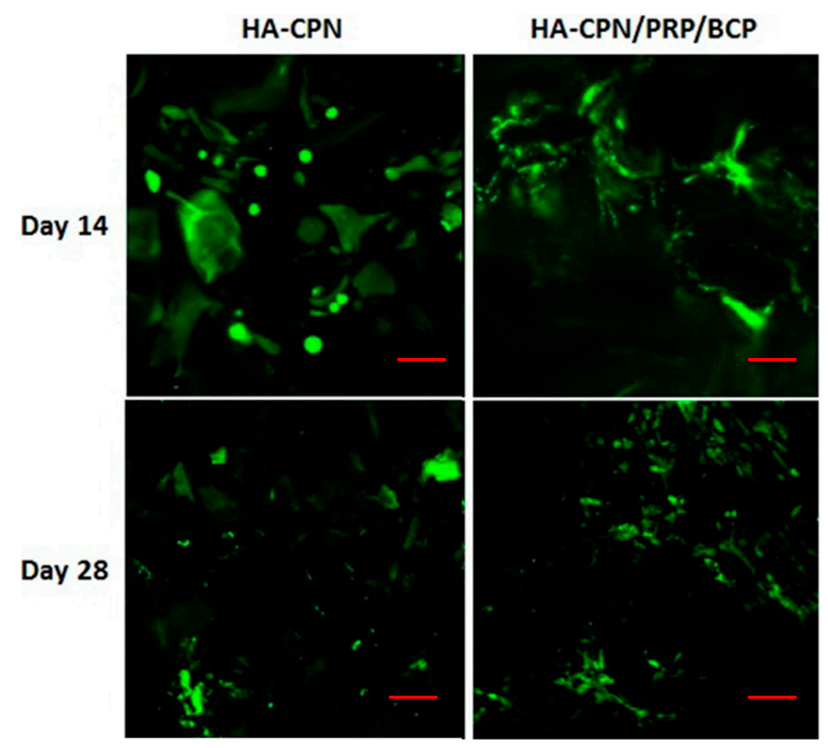

Figure 2. The viability of rASCs in HA-CPN and HA-CPN/PRP/BCP thermo-gelling hydrogel scaffolds by Live/Dead cell viability assays. Bar $=100 \mu \mathrm{m}$.

\subsection{Alkaline Phosphatase (ALP) Activities}

Initiation of bone mineralization could be noticed by recognizing the alkaline phosphatase (ALP) marker, which as a marker for early osteoblastic differentiation and commitment of stem cells towards the osteoblast phenotype [50]. As nucleation starts with the deposition of calcium with inorganic phosphates and leads to local calcification, hydrolysis of phosphate esters leads to elevated mineralization of ECM and stimulates osteogenic differentiation [51]. Thus, ALP could be considered as a worthy measurement tool to determine the extent of osteo-differentiation of stem cells. Figure 3 indicates continued ALP production throughout the 28-day culture period for both groups; nonetheless, the ALP activity of rASCs in HA-CPN/PRP/BCP was significantly higher than in HA-CPN at all time points. Therefore, combinatory effects from PRP and BCP accelerated rASCs differentiation toward the osteoblast lineage, with ASCs in HA-CPN/PRP/BCP exhibiting enhanced ALP activity. Comparing the trend of ALP expression at various time points in different thermo-gelling hydrogel scaffolds, HA-CPN/PRP/BCP clearly showed dominance in rASCs differentiation [52].

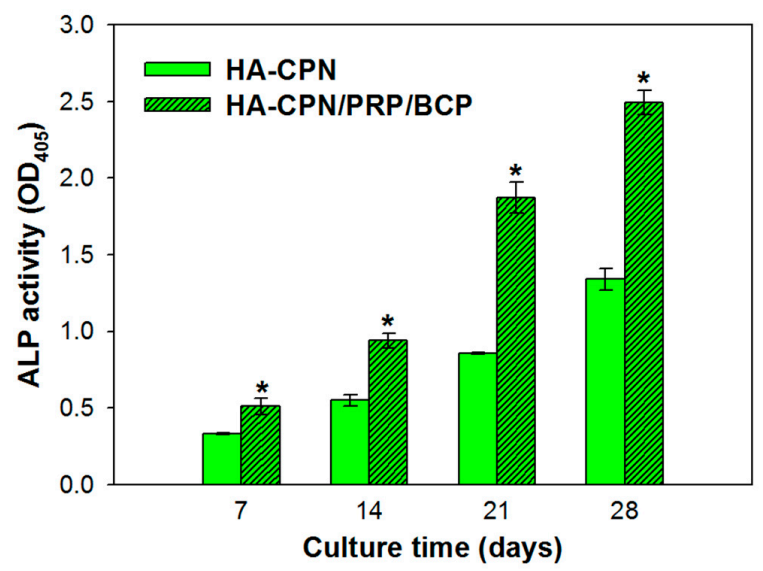

Figure 3. The time-dependent changes of alkaline phosphatase (ALP) activities of rASCs in HA-CPN and HA-CPN/PRP/BCP thermo-gelling hydrogel scaffolds. ${ }^{*} p<0.05$ compared with HA-CPN. 


\subsection{Von Kossa, Alizarin Red and ALP Stains}

For qualitative evaluation of the mineralization of ASCs in HA-CPN and HA-CPN/PRP/BCP, the cryosection slices of cell/scaffold constructs were subject to von Kossa, Alizarin red (AR) and ALP stains. The mineralized nodules were revealed by staining with von Kossa staining reagents while calcium deposition on matured ECM was determined by AR stain. As shown in Figure 4, both von Kossa and Alizarin red stains revealed time-dependent mineralization of rASCs in HA-CPN hydrogel matrix. Nonetheless, the staining intensity was dramatically enhanced in HA-CPN/PRP/BCP. The concentration of mineralized ECM stained dark brown to black from von Kossa stain increased with culture time and appeared early for rASCs in HA-CPN/PRP/BCP than in HA-CPN, indicating more mineralized nodules formation with rapid development of osteoblast phenotype to form a mineralized matrix, which could be ascribed to the osteogenic natures of incorporated PRP/BCP in HA-CPN. More prominent AR staining was also evident in HA-CPN/PRP/BCP, in which nodules stained in red color originating from calcium ions in mineralized ECM secreted by osteo-differentiated rASCs increased with culture time. Since the capacity to deposit minerals is a marker for mature osteoblasts, it could be concluded that rASCs encapsulated in HA-CPN/PRP/BCP develop into an osteoblast phenotype faster than in HA-CPN, with accelerated mineralization stage to deposit mineralized ECM [53].

Considering ALP staining results in Figure 4, positive ALP stains (violet color) for rASCs in HA-CPN/PRP/BCP evidence the increase of intracellular ALP activity with culture time, particularly for cell constructs cultured longer than 2 weeks. On the other hand, minimum ALP staining intensity was observed for HA-CPN. HA-CPN showed light violet color while thick violet color dots with brownish red shadows were observed in HA-CPN/PRP/BCP on day 7. For rASCs in HA-CPN/PRP/BCP, violet and reddish brown violet ALP stains were observed on day 14 and day 21, respectively. The staining intensity turned much stronger and was a dark purple color on day 28 , indicating continued elevation of ALP activity in HA-CPN/PRP/BCP. Taken together, the enhanced ALP staining intensity for rASCs in HA-CPN/PRP/BCP strongly endorse elevated ALP activity of rASCs in the presence of PRP and BCP, especially for cell constructs cultured longer than 14 days, which is consistent with the trend observed by biochemical assays (Figure 3).

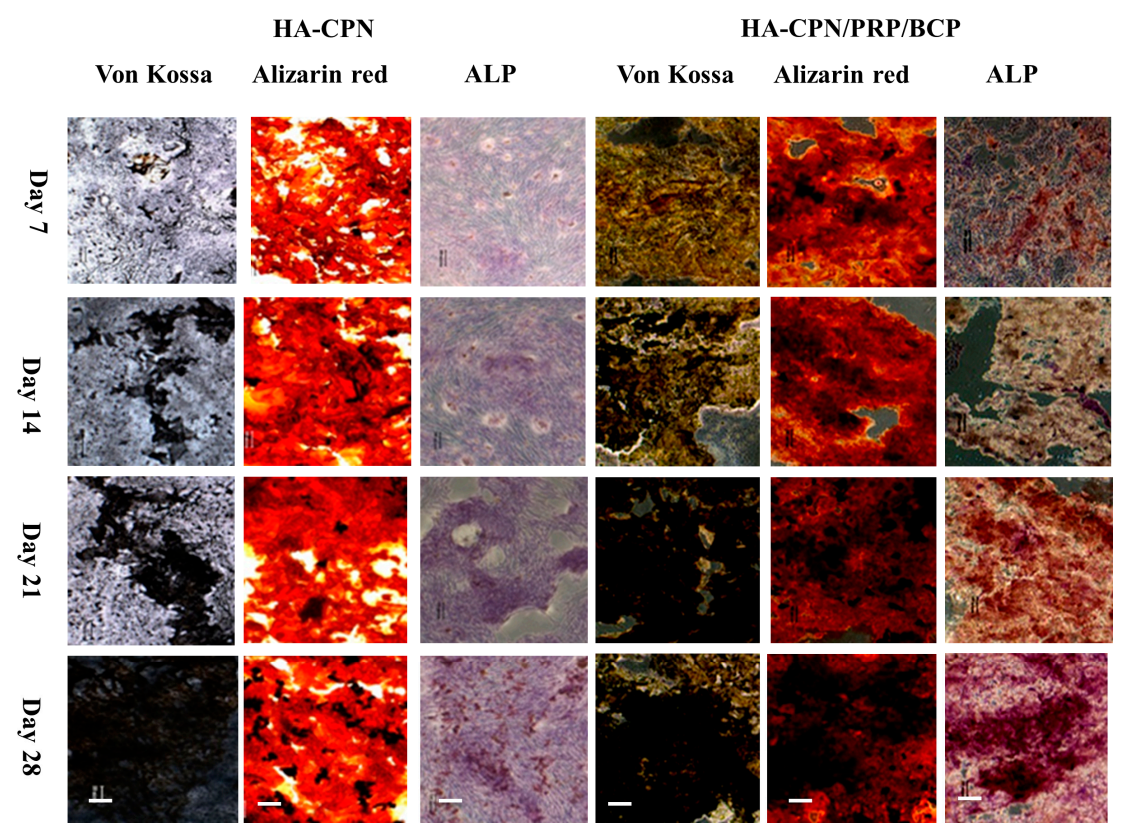

Figure 4. The von Kossa, Alizarin red and alkaline phosphatase (ALP) staining of cryosection slices of rASCs in HA-CPN and HA-CPN/PRP/BCP thermo-gelling hydrogel scaffolds. Bar $=100 \mu \mathrm{m}$. 


\subsection{Calcium Content}

A quantitative determination of calcium content was used to cross confirm the calcium-based mineralization of rASCs (Figure 5). By extracting Alizarin red S (ARS) that binds to $\mathrm{Ca}^{2+}$ on cell surface with $10 \%$ cetylpyridinium chloride, quantitative evaluation of rASCs mineralization could be achieved by determining $\mathrm{OD}_{540}$ and augment the qualitative AR staining results shown in Figure 4 . Since stem cells start depositing calcium during their later cell proliferation phase, the extent of calcium deposition depends strongly on the duration of the cell culture period [54]. As shown in Figure 5, the calcium content represented by $\mathrm{OD}_{540}$ increased rapidly with time from day 7 to day 28 in both hydrogel scaffolds. Nonetheless, the HA-CPN/PRP/BCP group showed significantly higher calcium content than the HA-CPN group throughout the 28-day culture period, which is in agreement with the qualitative AR staining images shown in Figure 4 and in line with ALP activity increase shown in Figure 3.

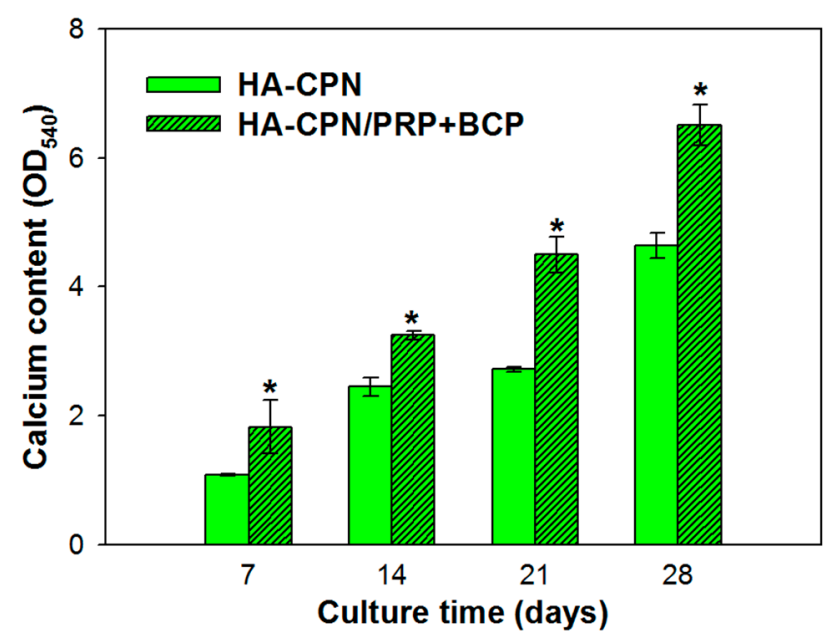

Figure 5. The calcium content of rASCs cultured in HA-CPN and HA-CPN/PRP/BCP thermo-gelling hydrogel scaffolds. ${ }^{*} p<0.05$ compared with HA-CPN.

\subsection{Scanning Electron Microscopy/Energy Dispersive X-Ray (SEM/EDX) Analysis}

To examine cell morphology and mineralization, scanning electron microscopy/energy dispersive X-ray (SEM/EDX) analysis of cell/scaffold constructs at day 14 and 28 was attempted and the results are reported in Figure 6. Although cell morphology variance may arise due to rASCs being entrapped in the hydrogel matrix rather than adhered to a substrate surface, a morphological change could still be observed when rASCs were cultured in HA-CPN/PRP/BCP, which showed better cell spreading than in HA-CPN. This implies better osteogenesis of rASCs since stem cells will flatten and spread when undergoing osteogenesis [55]. In addition, the presence of mineralized nodules on the cell surface is higher for rASCs in HA-CPN/PRP/BCP compared to HA-CPN, which underlines the importance of the combinatory cues from PRP and BCP in HA-CPN/PRP/BCP for effective mineralization of rASCs [52]. It is well recognized that mineral formation during stem cell culture implied cellular osteoblastic differentiation [56]. As deposition of calcium phosphate leads to mineralization, the mineralization of inorganic phosphates on cell surface could be deemed as prime evidence for osteo-differentiation of rASCs [57]. Thus, the white mineral deposition from SEM observation could qualitatively identify mineralization, which could be further analyzed quantitatively through elemental analysis by EDX analysis. The EDX spectra associated with each SEM image was shown in Figure 6, from which the atomic percentages of elements in minerals deposited by rASCs were determined for quantitative comparison. As shown in Figure 6, the extent of mineralization increased from day 14 to day 28 and higher percentages of $\mathrm{Ca}$ and $\mathrm{P}$ were found for HA-CPN/PRP/BCP than HA-CPN. Specifically, the Ca/P atomic percentage was $6.64 \% / 4.52 \%$ for $\mathrm{HA}-\mathrm{CPN} / \mathrm{PRP} / \mathrm{BCP}$ at 
day 14 and $7.46 \% / 5.55 \%$ at day 28. In comparison, the $\mathrm{Ca} / \mathrm{P}$ atomic percentage was only $1.01 \% / 0.72 \%$ at day 14 and 3.85\%/2.74\% at day 28 for HA-CPN. Comparing HA-CPN/PRP/BCP with HA-CPN, the $\mathrm{Ca}$ and $\mathrm{P}$ atomic percentage increase was 6.6-fold and 6.3-fold on day 14 and 1.9-fold and 2.0-fold on day 28 , indicating early and accelerated mineralization of rASCs in HA-CPN/PRP/BCP. Furthermore, the $\mathrm{Ca} / \mathrm{P}$ ratios in HA-CPN and HA-CPN/PRP/BCP were between 1.4 and 1.5 and close to that of bone, whose mineral primarily consists of $\mathrm{Ca}$ and $\mathrm{P}$ with a $\mathrm{Ca} / \mathrm{P}$ ratio from 1.4-1.7 [58]. Therefore, the atomic percentage values of $\mathrm{Ca}$ and $\mathrm{P}$ from EDX thus further demonstrate the potential application of $\mathrm{HA}-\mathrm{CPN} / \mathrm{PRP} / \mathrm{BCP}$ for bone regeneration.

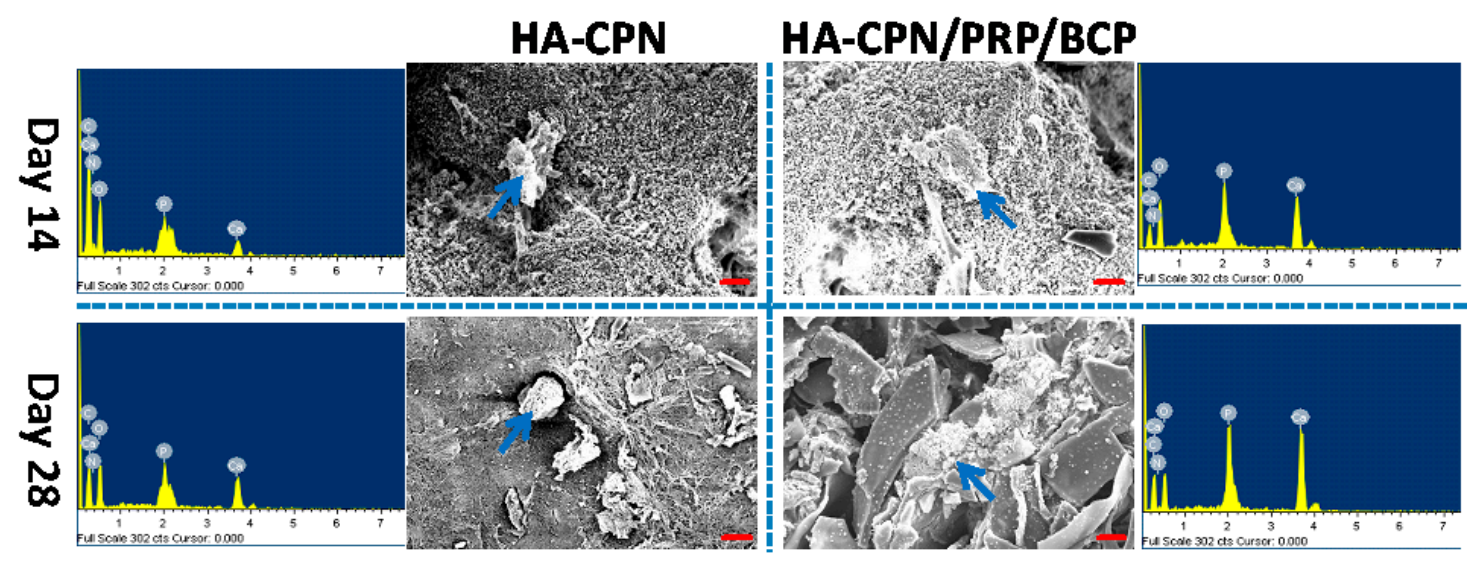

Figure 6. Scanning electron microscopy (SEM) micrographs and energy dispersive X-ray (EDX) measurements for detecting mineralization of rASCs in HA-CPN and HA-CPN/PRP/BCP thermo-gelling hydrogel scaffolds. The arrow in each SEM image indicates the place subject to EDX analysis with the spectrum shown besides the SEM image. Bar $=20 \mu \mathrm{m}$.

\subsection{Gene Expression by Quantitative Real-Time Polymerase Chain Reaction (qRT-PCR)}

The analysis of osteogenic gene expression could endorse the successful differentiation of rASCs into the osteoblast lineage. Thus, we further compared the relative mRNA expressions of major osteogenic differentiation marker genes (ALP, collagen type 1 (COL I), and osteocalcin (OCN)) of rASCs cultured in HA-CPN and HA-CPN/PRP/BCP (Figure 7). Being expressed at the early to middle stages of osteo-differentiation, ALP and COL were up-regulated during the first 2 weeks of cell culture without further increase of mRNA expression after day 21 [59]. On the other hand, the late expression of OCN could be confirmed from the continued increase of mRNA expression up to 28 days [60]. The scaffold-dependent analysis on gene expression further endorses the effect of $\mathrm{PRP} / \mathrm{BCP}$ in controlling the expression of various osteogenic markers. Indeed, HA-CPN/PRP/BCP showed a significant enhancement of ALP and COL I gene expression over HA-CPN starting from day 7 , which is consistent with their time-dependent gene expression sequence during osteogenic differentiation. On the other hand, being a late marker for osteogenesis, OCN would be up-regulated at a later stage of cell culture. Therefore, a significant difference of OCN mRNA expression was only noted between HA-CPN and HA-CPN/PRP/BCP after 14 days. Overall, we can infer that response of rASCs to BCP as well as PRP in HA-CPN leads to the difference in gene expression levels and control the time sequence of up-regulation of osteogenic genes. Considering the accelerated development of osteogenic phenotype of rASCs in HA-CPN/PRP/BCP in vitro, we proceeded with in vivo experiments to test the in vivo bone regeneration potential of $\mathrm{HA}-\mathrm{CPN} / \mathrm{PRP} / \mathrm{BCP} / \mathrm{rASC}$. 

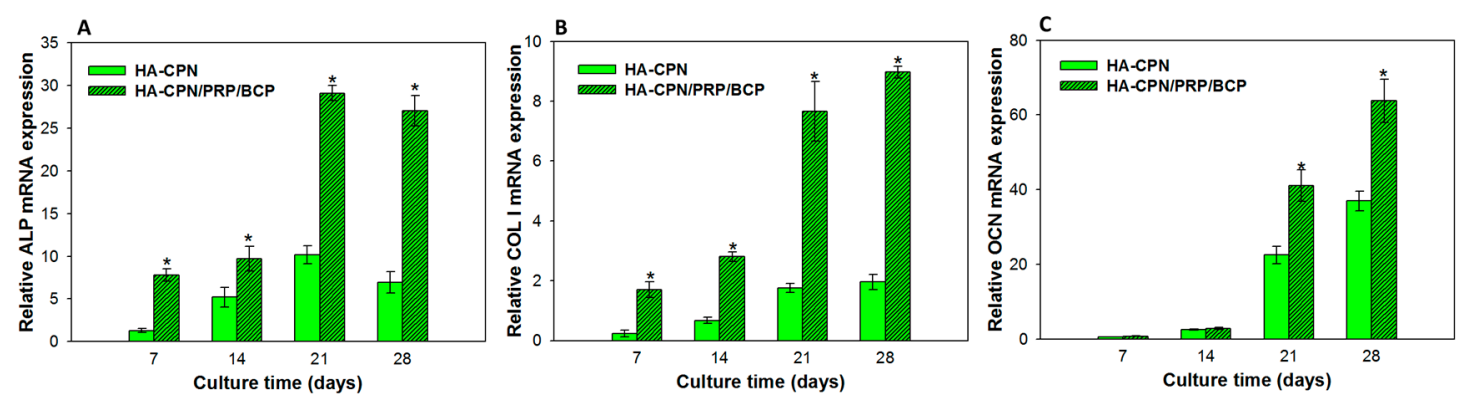

Figure 7. Osteogenic gene expression levels of rASCs after cultured in HA-CPN or HA-CPN/PRP/BCP thermo-gelling hydrogel scaffolds. Alkaline phosphatase (ALP) (A), collagen type 1 (COL I) (B) and osteocalcin $(\mathrm{OCN})(\mathrm{C})$ gene expression was quantified using quantitative real-time PCR.* $p<0.05$ compared with HA-CPN.

\subsection{In Vivo Studies}

After investigating in vitro osteogenesis, the critical size cranial bone defect model created in rabbits was used to test the in vivo bone regeneration potential of allogenic rASCs in $\mathrm{HA}-\mathrm{CPN} / \mathrm{PRP} / \mathrm{BCP}$. The HA-CPN/PRP/BCP/rASCs construct was cultured in vitro for 21 days prior to implantation. Since the 16-week animal experiment period did not lead to infection or inflammation symptoms around the implant sites and all rabbits stayed alive, we could confirm the in vivo biocompatibility of HA-CPN/PRP/BCP. One and 16 weeks post-implantation, the animals underwent computed tomography (CT) examination to evaluate new bone formation (Figure 8A). The 3D reconstructed CT images at week 1 showed some bone formation starting from one end and penetrated towards the center of the defect zone, without bridging the defect. After 16 weeks, the image density was elevated obviously with bone formation throughout the scaffold. The new bone was compact and bridged between the two ends of the circular defect and the defect was mostly covered with neo-bone formation based on the CT image density. For the control implanted with HA-CPN, negligible bone formation was found from CT images after 16 weeks. After sacrificing all animals at week 16, the specimen was harvested and bone formation was examined through histological evaluation, including hematoxylin and eosin (H\&E), Masson's trichrome and immunohistochemical (IHC) staining of OCN, to cross-confirm the high-density area found in the CT image, was bone tissue (Figure 8B). From the H\&E stain, osteoblasts in the bone matrix were observed together with osteoid formation, indicating bone growth in the defect region. Residual scaffold materials (labelled as S) could be observed 16 weeks after in vivo implantation. Masson's trichrome stain further clearly revealed bone formation as collagen in the osteoid was stained blue in sections of implanted HA-CPN/PRP/BCP/ASCs constructs as differentiated from rASCs deposited bone matrix (osteoid) and were embedded in the newly synthesized ECM. Osteoid is the organic portion of the bone matrix that is secreted by osteoblasts during new bone formation [61]. It contained several specific proteins with COL I being the predominant one and the rest being ground substance. Therefore, the development of new bone tissue may be verified from mineralized osteoid and adjacent bone cells. From IHC staining, the major ground substance in osteoid, OCN, could be identified in tissue sections, confirming that differentiated rASCs displayed an osteoblast phenotype. Taken together, the histological and IHC staining results support active osteogenesis from implanted rASCs and the observation that injected cell mass in the HA-CPN/PRP/BCP scaffold has formed new bone tissue. 
A
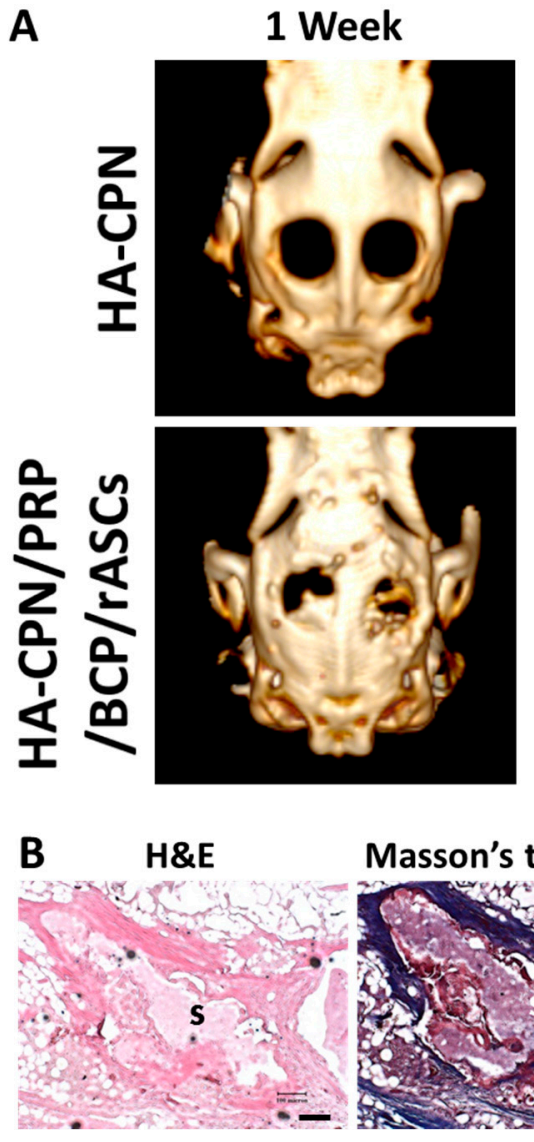

16 Weeks
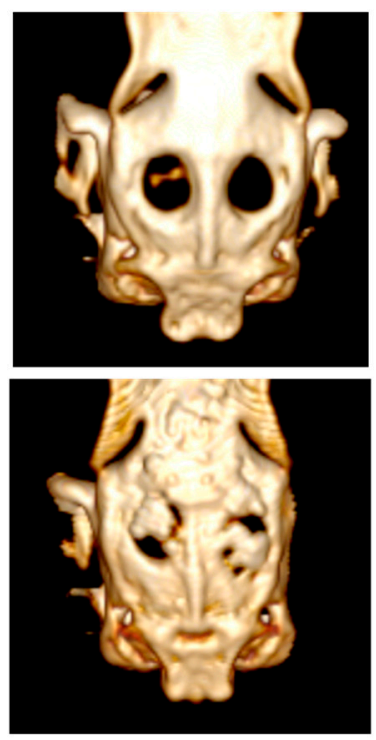

Masson's trichrome

OCN

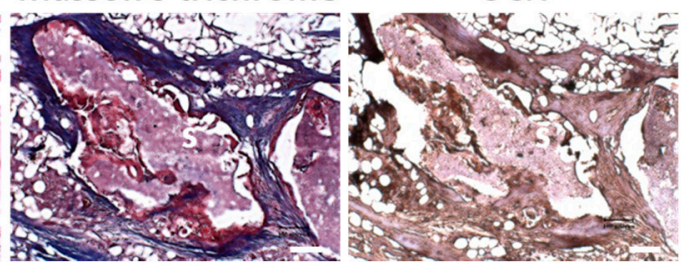

Figure 8. (A) The computed tomography (CT) scanning images of rabbit calvarial defects filled with $\mathrm{HA} / \mathrm{CPN}$ and HA-CPN/PRP/BCP/rASCs 1 and 16 weeks post-implantation. (B) Hematoxylin and eosin (H\&E), Masson's trichrome and immunohistochemical staining of OCN of implanted $\mathrm{HA}-\mathrm{CPN} / \mathrm{PRP} / \mathrm{BCP} / \mathrm{rASC}$ in rabbit calvarial defects 16 weeks post-implantation. Bar $=100 \mu \mathrm{m}$. $S$ indicates remaining scaffold material.

\section{Materials and Methods}

\subsection{Materials}

$\mathrm{N}$-isopropylacrylamide (NIPAM) and 2,2-azoisobutyronitrile were acquired from Sigma-Aldrich (St Louis, MO, USA) and were recrystallized prior to use from methanol and hexane, respectively. Chitosan (molecular weight $=1.5 \times 10^{5} \mathrm{Da}$ ) and 2-morpholinoethane sulfonic acid (MES) was purchased from Sigma-Aldrich (St Louis, MO, USA). N-Hydroxysuccinimide (NHS) and 1-ethyl-3-(3-dimethylaminopropyl) carbodiimide (EDC) were OBTAINED from Acros Organics, Thermo Fisher Scientific (Geel, Belgium). Hyaluronic acid (HA) (molecular weight $=1.3 \times 10^{6} \mathrm{Da}$ ) was obtained from Bloomage Freda Biopharm Co. (Jinan, China). Dulbecco's modified Eagle medium (DMEM, Gibco, Thermo Fisher Scientific, Waltham, MA, USA) and fetal bovine serums (FBS, HyClone, Thermo Fisher Scientific, Waltham, MA, USA) were prearranged for cell culture. Biphasic calcium phosphate (BCP) microparticles (0.5-1 mm particle size) contained $60 \%(w / w)$ of beta-tricalcium phosphate ( $\beta$-TCP) and $40 \%(w / w)$ hydroxyapatite (HAP) were provided by Berkeley Advanced Biomaterials, Inc. (San Leandro, CA, USA). CellTiter AQueous One Solution Reagent for cell proliferation assay was supplied by Promega Life Sciences (Madison, WI, USA). 


\subsection{Synthesis of Hyaluronic Acid-g-Chitosan-G-Poly(N-Isopropylacrylamide) (HA-CPN)}

The HA-CPN copolymer was prepared as reported previously [23]. Briefly, carboxylic acid terminated PNIPAM (PNIPAM-COOH) was readily prepared in benzene by free radical polymerization between NIPAM with mercaptoacetic acid as a chain-terminating agent and 2,2-azoisobutyronitrile as an initiator. Chitosan-g-poly(N-isopropylacrylamide) (CPN) was prepared from $0.5 \mathrm{~g}$ of chitosan and $5 \mathrm{~g}$ of PNIPAM-COOH in $50 \mathrm{~mL}$ MES buffer (pH 5.0) using EDC and NHS as crosslinking agents. After reacting for $12 \mathrm{~h}$ at $25^{\circ} \mathrm{C}$ and $180 \mathrm{rpm}$, temperature of the solution was raised to $50{ }^{\circ} \mathrm{C}$ for complete recovery of the copolymer by thermal precipitation. For the synthesis of HA-CPN copolymer, CPN prepared above was mixed with HA $(0.25 \mathrm{~g})$ in $100 \mathrm{~mL}$ of $0.1 \mathrm{M}$ MES buffer (pH 5) and the grafting reaction was carried out at $25^{\circ} \mathrm{C}$ and $180 \mathrm{rpm}$ for $12 \mathrm{~h}$ in the presence of EDC and NHS. After completing the reaction, impurities and residual HA were removed by the thermal precipitation at $50{ }^{\circ} \mathrm{C}$. The final HA-CPN copolymer used for forming the thermo-gelling hydrogel scaffold was purified by dialysis at $4{ }^{\circ} \mathrm{C}$ for 4 days and freeze-dried for storage at room temperature in a desiccator.

\subsection{Preparation of Platelet-Rich Plasma (PRP)}

The preparation of PRP from rabbits by double centrifugation followed the procedures described in our previous report [45]. The procedures were approved by the Institutional Animal Care and Use Committee of Chang Gung University (IACUC Approval No.: CGU13-063, 30 September 2013). In short, $\sim 30 \mathrm{~mL}$ of whole blood was withdrawn from ear vessels of rabbits into a tube that contained a citrate phosphate dextrose solution as an anticoagulant. The whole blood was centrifuged at $400 \times g$ for $10 \mathrm{~min}$ to separate the platelet layer from the plasma and red blood cells. The lower red blood cell layer was discarded while the middle platelet layer and the upper plasma layer were collected and further centrifuged at $800 \times g$ for $10 \mathrm{~min}$. The PRP was collected as the precipitated platelet layer with part of the plasma layer. The platelet number in whole blood and PRP were determined by a hematology analyzer (CELL-DYN Emerald, Abbott, Abbott Park, IL, USA) to check the quality of PRP obtained by this method.

\subsection{Isolation of Rabbit Adipose-Derived Stem Cells (rASCs)}

The animal experiments were approved by the Institutional Animal Care and Use Committee of Chang Gung University (IACUC Approval No.: CGU13-140, 18 March 2014) and confirmed to the standards of the Association for Assessment and Accreditation of Laboratory Animal Care. Rabbit adipose-derived stem cells (rASCs) were harvested and isolated according to our former report [51]. Briefly, fat tissue was harvested from a rabbit's inguinal area and diced into small pieces. The diced fat tissue was washed extensively with phosphate buffered saline (PBS), and digested with $0.05 \%$ collagenase in a $37^{\circ} \mathrm{C}$ water bath shaker at $165 \mathrm{rpm}$ for $30 \mathrm{~min}$. The enzyme activity was neutralized by adding an equal volume of DMEM/10\% FBS, and centrifuged at $250 \times g$ for $10 \mathrm{~min}$ to obtain a high density cell pellet. After removing the supernatant, the cell pellet was re-suspended in $160 \mathrm{mM} \mathrm{NH}_{4} \mathrm{Cl}$ and incubated at room temperature for $10 \mathrm{~min}$ to lyse the contaminated red blood cells. The cell pellet was collected again by the same centrifugation step, filtered through a $100 \mu \mathrm{m}$ nylon mesh to remove cellular debris, placed in culture dishes and incubated overnight with DMEM at $37^{\circ} \mathrm{C}$ in a $5 \% \mathrm{CO}_{2}$ incubator for attachment of rASCs to dish surface. Following incubation, the culture dishes were washed extensively with PBS to remove residual no-adherent red blood cells to obtain rASCs-enriched cell population.

\subsection{In Vitro Culture of rASCs in HA-CPN and HA-CPN/Platelet-Rich Plasma/Biphasic Calcium Phosphate} $(H A-C P N / P R P / B C P)$

For the culture of rASCs in the thermo-gelling hydrogel, $10 \%(w / v)$ HA-CPN or $10 \%(w / v)$ $\mathrm{HA}-\mathrm{CPN} / 10 \%(v / v) \mathrm{PRP} / 3 \%(w / v) \mathrm{BCP}$ solution were prepared in DMEM at $4{ }^{\circ} \mathrm{C}$. Suspension of rASCs was mixed at room temperature with $0.4 \mathrm{~mL}$ of HA-CPN or HA-CPN/PRP/BCP solution. 
The mixture was carefully transferred to a 24 -well cell culture plate and incubated at $37^{\circ} \mathrm{C}$ for $1 \mathrm{~h}$ at a cell seeding density of $1 \times 10^{5}$ cells / well. One milliliter of cell culture medium ( $90 \%$ DMEM, $10 \%$ FBS, $50 \mu \mathrm{mol} / 1 \mathrm{~L}$-ascorbic acid phosphate, $100 \mathrm{nmol} / \mathrm{L}$ dexamethasone, $10 \mathrm{mmol} / \mathrm{L}$ glycerol 2-phosphate and $1 \%(v / v)$ antibiotic-antimycotic) was added to each well and cell culture was carried out at $37^{\circ} \mathrm{C}$ in a humidified $5 \% \mathrm{CO}_{2}$ incubator with medium change on every 2 to 3 days.

\subsection{Cell Proliferation}

To determine the proliferation of ASCs, the viable cell number was determined by the 3-(4,5-dimethylthiazol-2-yl)-5-(3-carboxymethoxyphenyl)-2-(4-sulfophenyl)-2H tetrazolium (MTS) assay using the CellTiter AQueous One Solution Reagent. After cooling to $4{ }^{\circ} \mathrm{C}$ to reverse the cell/hydrogel constructs to a solution state, $200 \mu \mathrm{L}$ of cold DMEM was added to obtain cell suspension. The MTS assay were performed by adding $20 \mu \mathrm{L}$ of MTS solution to $200 \mu \mathrm{L}$ of cell suspension, followed by incubating at room temperature for $3 \mathrm{~h}$ in the absence of light. Colorimetric measurement of the formazan product was performed by measuring the optical density value at $490 \mathrm{~nm}\left(\mathrm{OD}_{490}\right)$ using an ELISA plate reader (BioTek Synergy HT, Winooski, VT, USA) [24].

\subsection{Live/Dead Assay}

The qualitative assessment on the cell viability of rASCs was evaluated using the Live/Dead Viability/Cytotoxicity kit (Molecular Probes, Thermo Fisher Scientific, Waltham, MA, USA). Once cultured for 21 days, the medium was removed from each well and samples were washed three times with PBS. A Live/Dead staining solution contained $2 \mu \mathrm{M}$ calcein AM (excitation $494 \mathrm{~nm}$, emission $517 \mathrm{~nm}$ ) and $5 \mu \mathrm{M}$ ethidium homodimer-1 (EthD-1) (excitation $528 \mathrm{~nm}$, emission $617 \mathrm{~nm}$ ) was prepared in DMEM, with calcein AM detecting live cell and EthD-1 for dead cell identification. The samples were incubated with the staining solution at $37^{\circ} \mathrm{C}$ for $30 \mathrm{~min}$ and stained cells were imaged under a Zeiss LSM 510 Meta confocal laser scanning microscope (Carl Zeiss Microscopy GmbH, Jena, Germany).

\subsection{ALP Activity}

To analyze the intracellular ALP activity, $800 \mu \mathrm{L}$ cold cell lysis solution containing $0.1 \%$ Triton X-100 and $5 \mathrm{mM} \mathrm{MgCl} 2$ was added to each well after PBS washing. After incubating at $4{ }^{\circ} \mathrm{C}$ for $10 \mathrm{~min}$ to lysis cells, the solution was centrifuged at $13,000 \times g$ for $10 \mathrm{~min}$ and the supernatant was examined for ALP activity using $p$-nitrophenyl phosphate as a substrate for the enzymatic hydrolysis reaction. Briefly, $50 \mu \mathrm{L}$ supernatant was reacted with $50 \mu \mathrm{L} p$-nitrophenyl phosphate $(5 \mathrm{mM})$ for $60 \mathrm{~min}$ at $37^{\circ} \mathrm{C}$ before adding $50 \mu \mathrm{L} 0.2 \mathrm{~N} \mathrm{NaOH}$ as a stop solution to denature ALP. The ALP activity was determined from the optical density value of the solution at $405 \mathrm{~nm}\left(\mathrm{OD}_{405}\right)$ using an enzyme-linked immunosorbent assay (ELISA) reader.

\subsection{Alizarin Red, Von Kossa and ALP Stains}

After detaching the cell-loaded hydrogel from each well, the sample was embedded in an optimal cutting temperature (OCT) compound. The sample in the cryomold was first placed at $-20{ }^{\circ} \mathrm{C}$ until the OCT compound becomes translucent, followed by transferring to $-80^{\circ} \mathrm{C}$ overnight. After removing from the cryomold, the frozen block was mounted on a chuck in a cryostat and slices (5 to $10 \mu \mathrm{m}$ ) were collected. The samples were fixed at $37^{\circ} \mathrm{C}$ in $4 \%$ formaldehyde for $3 \mathrm{~h}$ and washed with PBS before subject to different stains. For ALP stain, the sample was stained with ALP substrate solution containing fast blue RR $(2 \mathrm{mg} / \mathrm{mL})$ and 1-naphthyl phosphate sodium salt $(2 \mathrm{mg} / \mathrm{mL})$ in distilled de-ionized (DDI) water for $30 \mathrm{~min}$ at $37^{\circ} \mathrm{C}$. To detect mineralized nodules, Alizarin red stain was used by incubating samples in $2 \%$ Alizarin red S (ARS) solution in DDI water for $1 \mathrm{~h}$ at $37^{\circ} \mathrm{C}$. For von Kossa stain, samples were pre-treated with silver nitrate solution ( $5 \%$ in DDI water) for $20 \mathrm{~min}$ before placed in a UV box for UV light exposure for $2 \mathrm{~h}$. The sample was finally soaked in sodium thiosulfate (5\%) for $5 \mathrm{~min}$ to remove excess silver nitrate. 


\subsection{Calcium Content}

Alizarin red S (ARS) was used to quantify the calcium ion $\left(\mathrm{Ca}^{2+}\right)$ content in mineralized ECM of osteo-differentiated rASCs. The cell-seeded hydrogel scaffold was removed from wells of the culture plate and washed 3 times with $\mathrm{PBS}$ at $37^{\circ} \mathrm{C}$. After fixing with $4 \%$ glutaraldehyde solution (in $0.01 \mathrm{M}$ phosphate buffer) for $3 \mathrm{~h}$ at $37^{\circ} \mathrm{C}, 1 \mathrm{~mL}$ of ARS solution ( $2 \mathrm{~g}$ ARS in $100 \mathrm{~mL}$ DDI water) was added and incubated for $1 \mathrm{~h}$ at room temperature. After several washes with DDI water to remove excess dye, the sample was incubated with $1 \mathrm{~mL}$ of $10 \%$ cetylpyridinium chloride solution to elute the ARS-Ca ${ }^{2+}$ chelating complex. The solution was transferred to an ELISA reader (Synergy HT, BioTek, Winooski, Vermont, VT, USA) and the solution absorbance was determined at $540 \mathrm{~nm}\left(\mathrm{OD}_{540}\right)$.

\subsection{Scanning Electron Microscopy/Energy Dispersive X-Ray (SEM/EDX) Analysis}

The samples were firstly rinsed with $37{ }^{\circ} \mathrm{C}$ PBS and then fixed in $4 \%$ glutaraldehyde (in $0.1 \mathrm{M}$ phosphate buffer) at $37^{\circ} \mathrm{C}$. After subsequently fixation for another $3 \mathrm{~h}$, the samples were washed 3 times in PBS buffer at $37^{\circ} \mathrm{C}$ for $10 \mathrm{~min}$ each and then post-fixed in $1 \% \mathrm{OsO} 4$ (in $0.1 \mathrm{M}$ phosphate buffer) at $37^{\circ} \mathrm{C}$ for $2.5 \mathrm{~h}$. Later, samples were washed 3 times with DDI water and dehydrated in stepwise increasing concentrations of ethanol from $50 \%$ to $100 \%$. Lastly, the specimens were dried in a critical point dryer, sputter coated with gold, and examined under an S-3000N scanning electron microscope (Hitachi, Tokyo, Japan). The extent of cell mineralization was determined form the atomic percentage of elements using an energy dispersive X-ray (EDX) micro-analyzer (Horiba EX-250, Tokyo, Japan).

\subsection{Expression of Osteogenic Genes by $q R T-P C R$}

The expression of osteogenic differentiation marker genes was studied using qRT-PCR following standard protocols for RNA isolation and cDNA preparation. Total RNA of each specimen was isolated with TRIzol reagent (Invitrogen, Carlsbad, CA, USA) and dissolved in RNase-free water. The amount of RNA was determined by measuring the OD value at $260 \mathrm{~nm}\left(\mathrm{OD}_{260}\right)$ with a NanoDrop microvolume spectrophotometer (Thermo Fisher Scientific, Waltham, MA, USA). RNA quality was verified by measurement of $\mathrm{OD}_{260} / \mathrm{OD}_{280}$. The cDNA was prepared from $2 \mu \mathrm{g}$ of total RNA with Revert Aid First Strand cDNA Synthesis Kit in a final volume of $20 \mu \mathrm{L}$. The relative mRNA expression of ALP, OCN and COL I osteogenic marker genes was used for study of osteogenesis by designing the primer sequence using the Oligo 6.0 Primer Analysis Software Molecular Biology Insights, Inc. (Colorado Springs, CO, USA). For a single PCR reaction amounting to $20 \mu \mathrm{L}, 0.2 \mu \mathrm{L}$ of cDNA was used. To make the visualization of PCR products possible in real time, a SYBR Green I Supermix (Yeastern Biotech Co., Taipei, Taiwan) was used. A three temperature cycling, consisting of a denaturation step at $95{ }^{\circ} \mathrm{C}$ for $30 \mathrm{~s}$, a annealing step at $57.6{ }^{\circ} \mathrm{C}$ for $30 \mathrm{~s}$ and an extension step at $72{ }^{\circ} \mathrm{C}$ for $30 \mathrm{~s}$, was carried out in an iCycler iQ5 real-time detection system (Bio-Rad Laboratories Inc., Hercules, CA, USA). The specificity of each PCR reaction was assessed by performing melting curve analysis after each reaction. Glyceraldehyde-3-phosphate dehydrogenase (GAPDH) acted as a housekeeping control. Results were quantified for osteogenic marker genes using the $2^{-\Delta \Delta C t}$ relative quantification method. The expression of each gene was evaluated in triplicate.

\subsection{In Vivo Experiment}

The critical size calvarial bone defect model in rabbits was used to evaluate bone formation by implanting HA-CPN/PRP/BCP/ASCs in rabbit skull. Animal protocols were approved by the Institutional Animal Care and Use Committee of Chang Gung University (IACUC Approval No.: CGU13-035). New Zealand white male rabbits weighing 3-4 kg were utilized for the experimental studies. Animals were anesthetized with xylazine $(7 \mathrm{mg} / \mathrm{kg})$ and ketamine $(140 \mathrm{mg} / \mathrm{kg})$ and the scalp was sterilized with $75 \%$ alcohol solution. Animals were kept in single rooms and fed with standard animal feeds. For an assessment of bone regeneration, two $10 \mathrm{~mm}$ diameter circular 
defects were made at the calvarial bone of the rabbit. Five hundred microliter of HA-CPN/PRP/BCP solution containing $5 \times 10^{6}$ rASCs was cultured in vitro for 3 weeks before injecting into each defect. The control group was injected with $500 \mu \mathrm{L}$ of HA-CPN. Bone formation was examined by computed tomography (CT) examination using a CT scanner (Somatom Sensation 16, Siemens Healthcare $\mathrm{GmbH}$, Erlangen, Germany) 16 weeks post-operation. The CT image acquisition, processing, and manipulation procedures followed standard protocols at a medical facility. The animals were sacrificed 16-week post-implantation with overdosed pentobarbital to retrieve the implants for histological analysis. The samples were fixed in $10 \%$ formaldehyde and dehydrated by embedding in paraffin. After sectioning into $5 \mu \mathrm{m}$ slice sections, hematoxylin and eosin (H \& E), Masson's trichrome and IHC staining of OCN were carried out following standard protocols [62]. The images were recorded under an inverted optical microscope (Olympus IX-71, Tokyo, Japan).

\subsection{Statistical Analysis}

All data are reported as mean \pm standard deviation. Tukey's post hoc test was used to determine the difference between two groups with $p<0.05$ being considered statistically significant.

\section{Conclusions}

Thermo-gelling HA-CPN/PRP/BCP hydrogel scaffold is found to be a suitable injectable cell carrier for rASCs. In vitro culture of rASCs in HA-CPN/PRP/BCP exhibited better cell proliferation and enhanced osteogenic differentiation. From gene expression, tissue section staining, SEM/EDX and calcium content analysis, PRP/BCP boosts osteoblastic differentiation and ECM mineralization of rASCs in a HA-CPN gel matrix. Using allogenic rASCs in composite HA-CPN/PRP/BCP scaffold to repair critical size calvarial defects in rabbits, the $\mathrm{CT}$ analysis confirmed successful bone formation using the cell/hydrogel construct. The phenotypic markers for osteogenesis in the neo-bone tissue could be further identified from histology and IHC staining. Overall, the HA-CPN hydrogel scaffold fortified with PRP/BCP as osteo-inductive/osteo-conductive factors was shown to provide synergistic cues to promote the osteogenesis of rASCs in vitro and in vivo. This composite biomaterial could potentially be useful for development of an injectable cell carrier to assist bone regeneration in a non-load bearing defect site.

Author Contributions: H.T.L. and J.-P.C. conceived and designed the experiments; H.T.L. and M.-J.T. performed the experiments; H.T.L., M.-J.T. and J.-P.C. analyzed the data; H.-T.L., M.B. and J.-P.C. wrote the paper.

Acknowledgments: This work was supported by grants from Chang Gung Memorial Hospital (CRRPD2G0012, CRRPG3G0012, CMRPGBH0011 and BMRP 249) and the Ministry of Science and Technology (MOST105-2314-B-182-009).

Conflicts of Interest: The authors declare no conflict of interest.

\section{Abbreviations}

$\begin{array}{ll}\text { HA } & \text { Hyaluronic acid } \\ \text { PNIPAM } & \text { Poly(N-isopropylacrylamide) } \\ \text { HA-CPN } & \text { Hyaluronic acid-g-chitosan- } g \text {-PNIPAM } \\ \text { CPN } & \text { Chitosan- } g \text {-poly(N-isopropylacrylamide) } \\ \text { LCST } & \text { Lower critical solution temperature } \\ \text { PBS } & \text { Phosphate buffered saline } \\ \text { HAP } & \text { Hydroxyapatite } \\ \text { FBS } & \text { Fetal bovine serum } \\ \text { DMEM } & \text { Dulbecco's modified Eagle medium } \\ \text { ASCs } & \text { Adipose-derived stem cells } \\ \text { rASCs } & \text { Rabbit adipose-derived stem cells } \\ \text { ECM } & \text { Extracellular matrix }\end{array}$




$\begin{array}{ll}\text { H\&E } & \text { Hematoxylin and eosin } \\ \text { PRP } & \text { Platelet-rich plasma } \\ \text { SEM } & \text { Scanning electron microscopy } \\ \text { BCP } & \text { Biphasic calcium phosphate } \\ \beta-T C P & \beta \text {-Tricalcium phosphate } \\ \text { BTE } & \text { Bone tissue engineering } \\ \text { AR } & \text { Alizarin red } \\ \text { ARS } & \text { Alizarin red S } \\ \text { 3D } & \text { Three-dimensional } \\ \text { IHC } & \text { Immunohistochemical } \\ \text { CT } & \text { Computed tomography } \\ \text { OD } & \text { Optical density } \\ \text { SEM/EDX } & \text { Scanning electron microscopy/energy dispersive X-ray } \\ \text { ALP } & \text { Alkaline phosphatase } \\ \text { NHS } & \text { N-Hydroxysuccinimide } \\ \text { EDC } & \text { 1-Ethyl-3-(3-dimethylaminopropyl) carbodiimide } \\ \text { DDI } & \text { Distilled de-ionized } \\ \text { MES } & \text { 2-Morpholinoethane sulfonic acid } \\ \text { OCT } & \text { Optimal cutting temperature } \\ \text { qRT-PCR } & \text { Quantitative real-time polymerase chain reaction }\end{array}$

\section{References}

1. Sheikh, Z.; Sima, C.; Glogauer, M. Bone replacement materials and techniques used for achieving vertical alveolar bone augmentation. Materials 2015, 8, 2953. [CrossRef]

2. Rogers, G.F.; Greene, A.K. Autogenous bone graft: Basic science and clinical implications. J. Craniofac. Surg. 2012, 23, 323-327. [CrossRef] [PubMed]

3. Rose, F.R.; Oreffo, R.O. Bone tissue engineering: Hope vs hype. Biochem. Biophys. Res. Commun. 2002, 292, 1-7. [CrossRef] [PubMed]

4. Salgado, A.J.; Coutinho, O.P.; Reis, R.L. Bone tissue engineering: State of the art and future trends. Macromol. Biosci. 2004, 4, 743-765. [CrossRef] [PubMed]

5. LeGeros, R.Z. Calcium phosphate-based osteoinductive materials. Chem. Rev. 2008, 108, 4742-4753. [CrossRef] [PubMed]

6. Rizzi, S.C.; Heath, D.J.; Coombes, A.G.; Bock, N.; Textor, M.; Downes, S. Biodegradable polymer/hydroxyapatite composites: Surface analysis and initial attachment of human osteoblasts. J. Biomed. Mater. Res. 2001, 55, 475-486. [CrossRef]

7. Fellah, B.H.; Gauthier, O.; Weiss, P.; Chappard, D.; Layrolle, P. Osteogenicity of biphasic calcium phosphate ceramics and bone autograft in a goat model. Biomaterials 2008, 29, 1177-1188. [CrossRef] [PubMed]

8. Daculsi, G.; LeGeros, R.; Nery, E.; Lynch, K.; Kerebel, B. Transformation of biphasic calcium phosphate ceramics in vivo: Ultrastructural and physicochemical characterization. J. Biomed. Mater. Res. A 1989, 23, 883-894. [CrossRef] [PubMed]

9. Daculsi, G.; LeGeros, R.; Mitre, D. Crystal dissolution of biological and ceramic apatites. Calcif. Tissue Int. 1989, 45, 95-103. [CrossRef] [PubMed]

10. LeGeros, R. Calcium phosphate materials in restorative dentistry: A review. Adv. Dent. Res. 1988, 2, $164-180$. [CrossRef] [PubMed]

11. Marra, K.G.; Szem, J.W.; Kumta, P.N.; DiMilla, P.A.; Weiss, L.E. In vitro analysis of biodegradable polymer blend/hydroxyapatite composites for bone tissue engineering. J. Biomed. Mater. Res. 1999, 47, 324-335. [CrossRef]

12. Chen, J.-P.; Chang, Y.-S. Preparation and characterization of composite nanofibers of polycaprolactone and nanohydroxyapatite for osteogenic differentiation of mesenchymal stem cells. Colloids Surf. B Biointerfaces 2011, 86, 169-175. [CrossRef] [PubMed]

13. Baroth, S.; Bourges, X.; Goyenvalle, E.; Aguado, E.; Daculsi, G. Injectable biphasic calcium phosphate bioceramic: The hydros concept. Biomed. Mater. Eng. 2009, 19, 71-76. [PubMed] 
14. Slaughter, B.V.; Khurshid, S.S.; Fisher, O.Z.; Khademhosseini, A.; Peppas, N.A. Hydrogels in regenerative medicine. Adv. Mater. 2009, 21, 3307-3329. [CrossRef] [PubMed]

15. Akalp, U.; Bryant, S.J.; Vernerey, F.J. Tuning tissue growth with scaffold degradation in enzyme-sensitive hydrogels: A mathematical model. Soft Matter 2016, 12, 7505-7520. [CrossRef] [PubMed]

16. Tozzi, G.; De Mori, A.; Oliveira, A.; Roldo, M. Composite hydrogels for bone regeneration. Materials 2016, 9, 267. [CrossRef] [PubMed]

17. Kretlow, J.D.; Klouda, L.; Mikos, A.G. Injectable matrices and scaffolds for drug delivery in tissue engineering. Adv. Drug Deliv. Rev. 2007, 59, 263-273. [CrossRef] [PubMed]

18. Huayang, S.A.; Lu, J.; Zibiao, L. Biodegradable polyester thermogelling system as emerging materials for therapeutic applications. Macromol. Mater. Eng. 2018, 303, 1700656.

19. Liow, S.S.; Dou, Q.; Kai, D.; Karim, A.A.; Zhang, K.; Xu, F.; Loh, X.J. Thermogels: In situ gelling biomaterial. ACS Biomater. Sci. Eng. 2016, 2, 295-316. [CrossRef]

20. Vihola, H.; Laukkanen, A.; Valtola, L.; Tenhu, H.; Hirvonen, J. Cytotoxicity of thermosensitive polymers poly(N-isopropylacrylamide), poly(N-vinylcaprolactam) and amphiphilically modified poly(N-vinylcaprolactam). Biomaterials 2005, 26, 3055-3064. [CrossRef] [PubMed]

21. Cooperstein, M.A.; Canavan, H.E. Assessment of cytotoxicity of (N-isopropyl acrylamide) and poly(N-isopropyl acrylamide)-coated surfaces. Biointerphases 2013, 8, 19. [CrossRef] [PubMed]

22. Cho, J.H.; Kim, S.H.; Park, K.D.; Jung, M.C.; Yang, W.I.; Han, S.W.; Noh, J.Y.; Lee, J.W. Chondrogenic differentiation of human mesenchymal stem cells using a thermosensitive poly(N-isopropylacrylamide) and water-soluble chitosan copolymer. Biomaterials 2004, 25, 5743-5751. [CrossRef] [PubMed]

23. Chen, J.-P.; Cheng, T.-H. Preparation and evaluation of thermo-reversible copolymer hydrogels containing chitosan and hyaluronic acid as injectable cell carriers. Polymer 2009, 50, 107-116. [CrossRef]

24. Chen, J.P.; Cheng, T.H. Thermo-responsive chitosan-graft-poly(N-isopropylacrylamide) injectable hydrogel for cultivation of chondrocytes and meniscus cells. Macromol. Biosci. 2006, 6, 1026-1039. [CrossRef] [PubMed]

25. Chen, C.H.; Kuo, C.Y.; Chen, S.H.; Mao, S.H.; Chang, C.Y.; Shalumon, K.T.; Chen, J.P. Thermosensitive injectable hydrogel for simultaneous intraperitoneal delivery of doxorubicin and prevention of peritoneal adhesion. Int. J. Mol. Sci. 2018, 19, 1373. [CrossRef] [PubMed]

26. Levengood, S.L.; Zhang, M. Chitosan-based scaffolds for bone tissue engineering. J. Mater. Chem. B 2014, 2, 3161-3184. [CrossRef] [PubMed]

27. Liu, H.; Li, H.; Cheng, W.; Yang, Y.; Zhu, M.; Zhou, C. Novel injectable calcium phosphate/chitosan composites for bone substitute materials. Acta Biomater. 2006, 2, 557-565. [CrossRef] [PubMed]

28. Sendemir-Urkmez, A.; Jamison, R.D. The addition of biphasic calcium phosphate to porous chitosan scaffolds enhances bone tissue development in vitro. J. Biomed. Mater. Res. Part A 2007, 81, 624-633. [CrossRef] [PubMed]

29. Tan, H.; Gong, Y.; Lao, L.; Mao, Z.; Gao, C. Gelatin/chitosan/hyaluronan ternary complex scaffold containing basic fibroblast growth factor for cartilage tissue engineering. J. Mater. Sci. Mater. Med. 2007, 18, 1961-1968. [CrossRef] [PubMed]

30. Solchaga, L.A.; Dennis, J.E.; Goldberg, V.M.; Caplan, A.I. Hyaluronic acid-based polymers as cell carriers for tissue-engineered repair of bone and cartilage. J. Orthop. Res. 1999, 17, 205-213. [CrossRef] [PubMed]

31. Chung, C.; Burdick, J.A. Influence of three-dimensional hyaluronic acid microenvironments on mesenchymal stem cell chondrogenesis. Tissue Eng. Part A 2009, 15, 243-254. [CrossRef] [PubMed]

32. Liao, H.T.; Chen, C.T.; Chen, J.P. Osteogenic differentiation and ectopic bone formation of canine bone marrow-derived mesenchymal stem cells in injectable thermo-responsive polymer hydrogel. Tissue Eng. Part C Methods 2011, 17, 1139-1149. [CrossRef] [PubMed]

33. Chen, J.-P.; Tsai, M.-J.; Liao, H.-T. Incorporation of biphasic calcium phosphate microparticles in injectable thermoresponsive hydrogel modulates bone cell proliferation and differentiation. Colloids Surf. B Biointerfaces 2013, 110, 120-129. [CrossRef] [PubMed]

34. Gimble, J.; Guilak, F. Adipose-derived adult stem cells: Isolation, characterization, and differentiation potential. Cytotherapy 2003, 5, 362-369. [CrossRef] [PubMed]

35. Plachokova, A.S.; van den Dolder, J.; Stoelinga, P.J.; Jansen, J.A. Early effect of platelet-rich plasma on bone healing in combination with an osteoconductive material in rat cranial defects. Clin. Oral Implant. Res. 2007, 18, 244-251. [CrossRef] [PubMed] 
36. Su, J.; Xu, H.; Sun, J.; Gong, X.; Zhao, H. Dual delivery of bmp-2 and bfgf from a new nano-composite scaffold, loaded with vascular stents for large-size mandibular defect regeneration. Int. J. Mol. Sci. 2013, 14, 12714. [CrossRef] [PubMed]

37. Lacci, K.M.; Dardik, A. Platelet-rich plasma: Support for its use in wound healing. Yale J. Biol. Med. 2010, 83, 1-9. [PubMed]

38. Marx, R.E. Platelet-rich plasma: Evidence to support its use. J. Oral Maxillofac. Surg. 2004, 62, 489-496. [CrossRef] [PubMed]

39. Liao, H.-T.; Marra, K.G.; Rubin, J.P. Application of platelet-rich plasma and platelet-rich fibrin in fat grafting: Basic science and literature review. Tissue Eng. Part B Rev. 2014, 20, 267-276. [CrossRef] [PubMed]

40. Feng, L.; Chang, W.; Tian, B.; Zeng, W.; Zhou, D. Bone regeneration combining platelet rich plasma with engineered bone tissue. J. Biomater. Tissue Eng. 2017, 7, 841-847. [CrossRef]

41. Liao, H.-T.; Chen, J.-P.; Lee, M.-Y. Bone tissue engineering with adipose-derived stem cells in bioactive composites of laser-sintered porous polycaprolactone scaffolds and platelet-rich plasma. Materials 2013, 6, 4911-4929. [CrossRef] [PubMed]

42. Griffin, X.L.; Smith, C.M.; Costa, M.L. The clinical use of platelet-rich plasma in the promotion of bone healing: A systematic review. Injury 2009, 40, 158-162. [CrossRef] [PubMed]

43. Son, S.R.; Sarkar, S.K.; Nguyen-Thuy, B.L.; Padalhin, A.R.; Kim, B.R.; Jung, H.I.; Lee, B.T. Platelet-rich plasma encapsulation in hyaluronic acid/gelatin-bcp hydrogel for growth factor delivery in bcp sponge scaffold for bone regeneration. J. Biomater. Appl. 2015, 29, 988-1002. [CrossRef] [PubMed]

44. Juan, S.; Yubao, L.; Yi, Z.; Qin, Z.; Lin, C.; Li, Z.; Mei, G.; Shibo, G. Characterization and cytocompatibility of biphasic calcium phosphate/polyamide 6 scaffolds for bone regeneration. J. Biomed. Mater. Res. B Appl. Biomater. 2010, 95B, 330-338.

45. Liao, H.T.; James, I.B.; Marra, K.G.; Rubin, J.P. The effects of platelet-rich plasma on cell proliferation and adipogenic potential of adipose-derived stem cells. Tissue Eng. Part A 2015, 21, 2714-2722. [CrossRef] [PubMed]

46. Gersch, R.P.; Glahn, J.; Tecce, M.G.; Wilson, A.J.; Percec, I. Platelet rich plasma augments adipose-derived stem cell growth and differentiation. Aesthet. Surg. J. 2017, 37, 723-729. [CrossRef] [PubMed]

47. Lai, F.; Kakudo, N.; Morimoto, N.; Taketani, S.; Hara, T.; Ogawa, T.; Kusumoto, K. Platelet-rich plasma enhances the proliferation of human adipose stem cells through multiple signaling pathways. Stem Cell Res. Ther. 2018, 9, 107. [CrossRef] [PubMed]

48. Paduano, F.; Marrelli, M.; Amantea, M.; Rengo, C.; Rengo, S.; Goldberg, M.; Spagnuolo, G.; Tatullo, M. Adipose tissue as a strategic source of mesenchymal stem cells in bone regeneration: A topical review on the most promising craniomaxillofacial applications. Int. J. Mol. Sci. 2017, 18, 2140. [CrossRef] [PubMed]

49. Ravichandran, R.; Venugopal, J.R.; Sundarrajan, S.; Mukherjee, S.; Ramakrishna, S. Precipitation of nanohydroxyapatite on plla/pblg/collagen nanofibrous structures for the differentiation of adipose derived stem cells to osteogenic lineage. Biomaterials 2012, 33, 846-855. [CrossRef] [PubMed]

50. Anderson, H.C.; Sipe, J.B.; Hessle, L.; Dhanyamraju, R.; Atti, E.; Camacho, N.P.; Millan, J.L.; Dhamyamraju, R. Impaired calcification around matrix vesicles of growth plate and bone in alkaline phosphatase-deficient mice. Am. J. Pathol. 2004, 164, 841-847. [CrossRef]

51. Park, K.W.; Yun, Y.P.; Kim, S.E.; Song, H.R. The effect of alendronate loaded biphasic calcium phosphate scaffolds on bone regeneration in a rat tibial defect model. Int. J. Mol. Sci. 2015, 16, 26738-26753. [CrossRef] [PubMed]

52. Liao, H.-T.; Shalumon, K.T.; Chang, K.-H.; Sheu, C.; Chen, J.-P. Investigation of synergistic effects of inductive and conductive factors in gelatin-based cryogels for bone tissue engineering. J. Mater. Chem. B 2016, 4, 1827-1841. [CrossRef]

53. Shalumon, K.; Kuo, C.-Y.; Wong, C.-B.; Chien, Y.-M.; Chen, H.-A.; Chen, J.-P. Gelatin/nanohyroxyapatite cryogel embedded poly(lactic-co-glycolic acid)/nanohydroxyapatite microsphere hybrid scaffolds for simultaneous bone regeneration and load-bearing. Polymers 2018, 10, 620. [CrossRef]

54. Ngiam, M.; Liao, S.; Patil, A.J.; Cheng, Z.; Chan, C.K.; Ramakrishna, S. The fabrication of nano-hydroxyapatite on PLGA and PLGA/collagen nanofibrous composite scaffolds and their effects in osteoblastic behavior for bone tissue engineering. Bone 2009, 45, 4-16. [CrossRef] [PubMed]

55. McBeath, R.; Pirone, D.M.; Nelson, C.M.; Bhadriraju, K.; Chen, C.S. Cell shape, cytoskeletal tension, and rhoa regulate stem cell lineage commitment. Dev. Cell 2004, 6, 483-495. [CrossRef] 
56. Zur Nieden, N.I.; Kempka, G.; Ahr, H.J. In vitro differentiation of embryonic stem cells into mineralized osteoblasts. Differentiation 2003, 71, 18-27. [CrossRef] [PubMed]

57. Heinemann, S.; Heinemann, C.; Bernhardt, R.; Reinstorf, A.; Nies, B.; Meyer, M.; Worch, H.; Hanke, T. Bioactive silica-collagen composite xerogels modified by calcium phosphate phases with adjustable mechanical properties for bone replacement. Acta Biomater. 2009, 5, 1979-1990. [CrossRef] [PubMed]

58. Fernandez, J.M.; Molinuevo, M.S.; Cortizo, M.S.; Cortizo, A.M. Development of an osteoconductive pcl-pdipf-hydroxyapatite composite scaffold for bone tissue engineering. J. Tissue Eng. Regen. Med. 2011, 5, e126-e135. [CrossRef] [PubMed]

59. Robert, A.W.; Angulski, A.B.B.; Spangenberg, L.; Shigunov, P.; Pereira, I.T.; Bettes, P.S.L.; Naya, H.; Correa, A.; Dallagiovanna, B.; Stimamiglio, M.A. Gene expression analysis of human adipose tissue-derived stem cells during the initial steps of in vitro osteogenesis. Sci. Rep. 2018, 8, 4739. [CrossRef] [PubMed]

60. Liu, H.; Wei, L.K.; Jian, X.F.; Huang, J.; Zou, H.; Zhang, S.Z.; Yuan, G.H. Isolation, culture and induced differentiation of rabbit mesenchymal stem cells into osteoblasts. Exp. Ther. Med. 2018, 15, 3715-3724. [CrossRef] [PubMed]

61. Yu, X.; Botchwey, E.A.; Levine, E.M.; Pollack, S.R.; Laurencin, C.T. Bioreactor-based bone tissue engineering: The influence of dynamic flow on osteoblast phenotypic expression and matrix mineralization. Proc. Natl. Acad. Sci. USA 2004, 101, 11203-11208. [CrossRef] [PubMed]

62. Lai, G.J.; Shalumon, K.T.; Chen, J.P. Response of human mesenchymal stem cells to intrafibrillar nanohydroxyapatite content and extrafibrillar nanohydroxyapatite in biomimetic chitosan/silk fibroin/nanohydroxyapatite nanofibrous membrane scaffolds. Int. J. Nanomed. 2015, 10, 567-584.

(C) 2018 by the authors. Licensee MDPI, Basel, Switzerland. This article is an open access article distributed under the terms and conditions of the Creative Commons Attribution (CC BY) license (http:// creativecommons.org/licenses/by/4.0/). 